\title{
Reliability of a commercially available threshold loading device in healthy subjects and in patients with chronic obstructive pulmonary disease
}

\author{
Rik Gosselink, Robert C Wagenaar, Marc Decramer
}

\begin{abstract}
Background - Threshold loading with the Nickerson and Keens' device is frequently applied in the training and assessment of inspiratory muscles. However, this equipment is not easily applied in clinical practice and training. A study was therefore designed to investigate the accuracy and reliability of the Threshold, a commercially available threshold loading device.

Methods - The resolution (accuracy) of the system was determined by measuring variation of pressure and flow during one minute in an experimental setup. The reproducibility and flow independence were then determined during threshold loading at six different inspiratory loads between $25 \%$ and $50 \%$ maximal inspiratory pressure (PImax) in 10 patients with chronic obstructive pulmonary disease (COPD) and eight healthy subjects.
\end{abstract}

Results - In the first experiment the mean variation of the sustained pressure for all loads was $1 \cdot 7 \%$. The mean coefficients of variation for pressure and flow measurements were $0 \cdot 2 \%$ and $3 \%$, respectively. In the second experiment the healthy subjects showed mean coefficients of variation for pressure and flow of $0.8 \%$ and $20.5 \%$, respectively, and the patients showed mean coefficients of variation of $0.6 \%$ and $14 \cdot 5 \%$, respectively.

Conclusions - During the in vitro experiment as well as during the experiments in patients with COPD and in healthy subjects only small variations in pressure were observed despite large variations in flow. The Threshold is a reliable and reproducible device for loading inspiratory muscles in patients with COPD as well as in healthy subjects.

(Thorax 1996;51:601-605)

Keywords: loaded breathing, respiratory muscles.

Department of Physiotherapy, VU

Hospital Amsterdam, The Netherlands

R C Wagenaar

Correspondence to: Dr R Gosselink.

Received 26 April 1995 Returned to authors 19 June 1995

Revised version received 3 November 1995 Accepted for publication 9 January 1996

Loading of respiratory muscles is used in several conditions such as training of respiratory muscles and assessment of endurance and mechanical efficiency. During training, as well as for assessment of endurance and mechanical efficiency of respiratory muscles, the load imposed on the respiratory muscles should be accurate, reproducible, and constant during inspiration. Two methods are described in the literature for loading the inspiratory muscles: inspiratory resistive loading ${ }^{1}$ and threshold loading. ${ }^{2}$ During inspiratory resistive loading the patient inspires through a mouthpiece and adapter with an adjustable diameter, thus imposing an inspiratory resistance. This resistance is flow-dependent. Adequate intensity of the load is only achieved if an adequate target pressure is obtained. ${ }^{3}$ Threshold loading allows a constant pressure independent of the inspiratory flow and pattern of breathing. The valve of the system, a weighted plunger, opens at a critical, adjustable pressure. When the valve opens the pressure in the system should remain constant.

Threshold loading was introduced by Nickerson and Keens ${ }^{2}$ and applied in a number of studies on testing ${ }^{4-11}$ and training ${ }^{51213}$ of the respiratory muscles. Recently, Eastwood and Hillman $^{14}$ showed improvements in the pressure/flow relationship by modification of the valve and the diaphragm of the Nickerson and Keens' device. The authors stress, however, that the inclination of the plunger to the valve is critical. This is a major disadvantage for clinical application in, for example, inspiratory muscle training. Another way of threshold loading is the solenoid valve described by Bardsley et $a l^{15}$ but this device is only loading during the onset of inspiration and not during the entire inspiration. In most studies the device of Nickerson and Keens is used but it is not commercially available and is cumbersome for application in home treatment. We therefore tested a commercially available threshold loading device (Threshold). The purposes of this study were: (1) to determine the resolution (accuracy) of the Threshold; (2) to assess the reproducibility of the pressure during a one minute period of loaded breathing; and (3) to evaluate the flow independence of the imposed pressures during a one minute period of loaded breathing.

\section{Methods}

The resolution (accuracy) of the threshold loading device Threshold was determined by measuring pressure and flow during one minute in an experimental set up in which, at random, seven different pressures $(20,25,30,35,40$, 45 , and $50 \mathrm{~cm} \mathrm{H}_{2} \mathrm{O}$ ) were obtained with a vacuum pump applied to the system. The suc- 


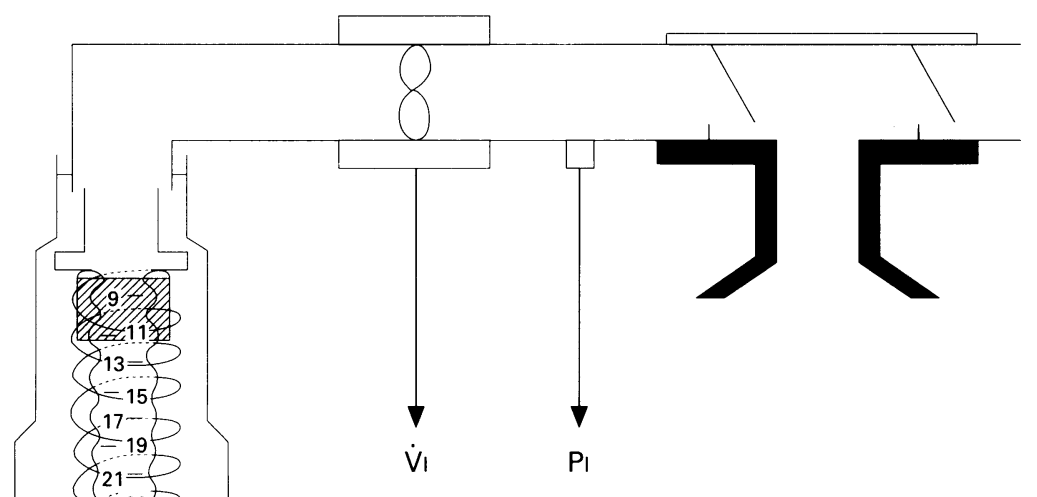

Table 1 Mean (SD) characteristics of patients and healthy subjects

\begin{tabular}{lcc}
\hline & Patients & Healthy subjects \\
\hline Age (years) & $61(5)$ & $64(4)$ \\
F:M & $4: 6$ & $3: 5$ \\
VC (\% pred) & $83(14)$ & $108(13)$ \\
FEV (1) & $0 \cdot 92(0 \cdot 23)$ & $3 \cdot 28(0 \cdot 84)$ \\
FEV (\% pred) & $31(9)$ & $107(17)$ \\
TLC (\% pred) & $126(13)$ & $108(14)$ \\
FRC/TLC pred (\%) & $89(14)$ & $62(14)$ \\
PImax (cm H H$\left._{2} \mathrm{O}\right)$ & $79(14)$ & $97(17)$ \\
PImax (\% pred) & $86(16)$ & $107(19)$ \\
\hline
\end{tabular}

$\mathrm{VC}=$ vital capacity; $\mathrm{FEV}_{1}=$ forced expiratory volume in one second; TLC = total lung capacity; FRC = forced residual capacity; PImax $=$ maximal inspiratory mouth pressure.

tion of the vacuum pump was increased until the valve opened. Pressure and flow were registered for one minute with a sample frequency of $20 \mathrm{~Hz}$.

The reproducibility and flow independence of the inspiratory loading were determined in healthy subjects and in patients with chronic obstructive pulmonary disease (COPD). Prior to the experiments pulmonary function was determined using standard lung function tests, according to American Thoracic Society recommendations. ${ }^{16}$ The vital capacity (VC) and forced expiratory volume in one second $\left(\mathrm{FEV}_{1}\right)$ were determined from the tracing yielding the largest sum of $\mathrm{VC}$ and $\mathrm{FEV}_{1}$. VC and $\mathrm{FEV}_{1}$ were related to normal values of Quanjer et al. ${ }^{17}$ Maximal inspiratory mouth pressure (PImax) was determined at residual volume using the technique and normal values of Black and Hyatt. ${ }^{18}$ Subsequently, the pressure and flow were measured during threshold loading at six different loads between $25 \%$ and $50 \%$ of PImax - that is, $25 \%, 30 \%, 35 \%, 40 \%, 45 \%$, and $50 \%$ - which were applied in a randomised order. The patients and healthy subjects breathed through each load for five minutes. No instructions were given on the breathing pattern. During the last minute of this period pressure and flow were measured with a sampling frequency of $20 \mathrm{~Hz}$. The first four minutes were used to habituate the subject to loaded breathing. Duty cycle (ratio of inspiratory time (TI) and respiratory cycle time (Tтот), TI/ TTOT) and respiratory rate (RR) were cal- culated from the pressure tracing. Transcutaneous oxygen saturation was measured at rest and during loaded breathing in order to exclude patients with hypoxaemia.

SUBJECTS

Ten patients with severe COPD and eight healthy subjects matched for age and sex were studied. Inclusion criteria included $\mathrm{FEV}_{1}$ less than $40 \%$ of the predicted value, age $45-75$ years, no cardiac diseases, absence of other serious illness (e.g. cerebrovascular diseases, rheumatism, arthritis, and malignancy). The healthy subjects were between 45 and 75 years old, had normal lung function, and no pathological conditions. The characteristics of the patients and healthy subjects included in the study are presented in table 1 . The procedure was explained to all the subjects and informed consent was obtained. The study was approved by the medical ethical board of the Vrije Universiteit Hospital.

\section{MATERIALS}

The inspiratory resistance (Threshold, HealthScan Products, New Jersey, USA) consists of a plastic cylinder and a valve which is pushed on the inspiratory port by a spring (fig 1). The inspiratory load is adjustable by loading the spring. In order to obtain pressures over $45 \mathrm{~cm} \mathrm{H}_{2} \mathrm{O}$ an additional spring is inserted with a double spring constant. The preset load was adjusted from the markers on the Threshold. Gradations on the device are given every $2 \mathrm{~cm}$ $\mathrm{H}_{2} \mathrm{O}$. Using the spring with the double spring constant, all values on the Threshold had to be doubled. The Threshold was attached to the inspiratory port of the Hans Rudolph valve (Kansas City, Missouri, USA); expiration was unimpeded. The inspiratory flow was registered by a mass flow sensor (Spirolog, Dräger, Germany), and the mouth pressure with a pressure transducer (P1OEZ, Gould Electronics) and an oscilloscope (Monitor 870, Datascope, Paramus, New Jersey, USA). Flow and pressure signals were digitised and stored in a computer (Olivetti M250). The software FAMS-LAB (Department of Psychology, Faculty of Human Movement Sciences, Free University) was used for data acquisition. Data analysis was carried out with the aid of PC-MATLAB (The MathWorks Inc, South Natick, NA). Lung function in patients and healthy subjects was measured with a wet spirometer (Pulmonet III, Sensormedics, Bilthoven, The Netherlands) and transcutaneous oxygen saturation with Nellcor 100 (Dräger, Germany).

In the first experiment a vacuum pump (Z25, Electrolux, The Netherlands) and an adjustable transformer (Philips, The Netherlands) were used.

\section{DATA ANALYSIS}

In the first experiment variation of pressures (maximum minus minimum values - that is, the mean range) during the one minute measurement was compared with the mean 

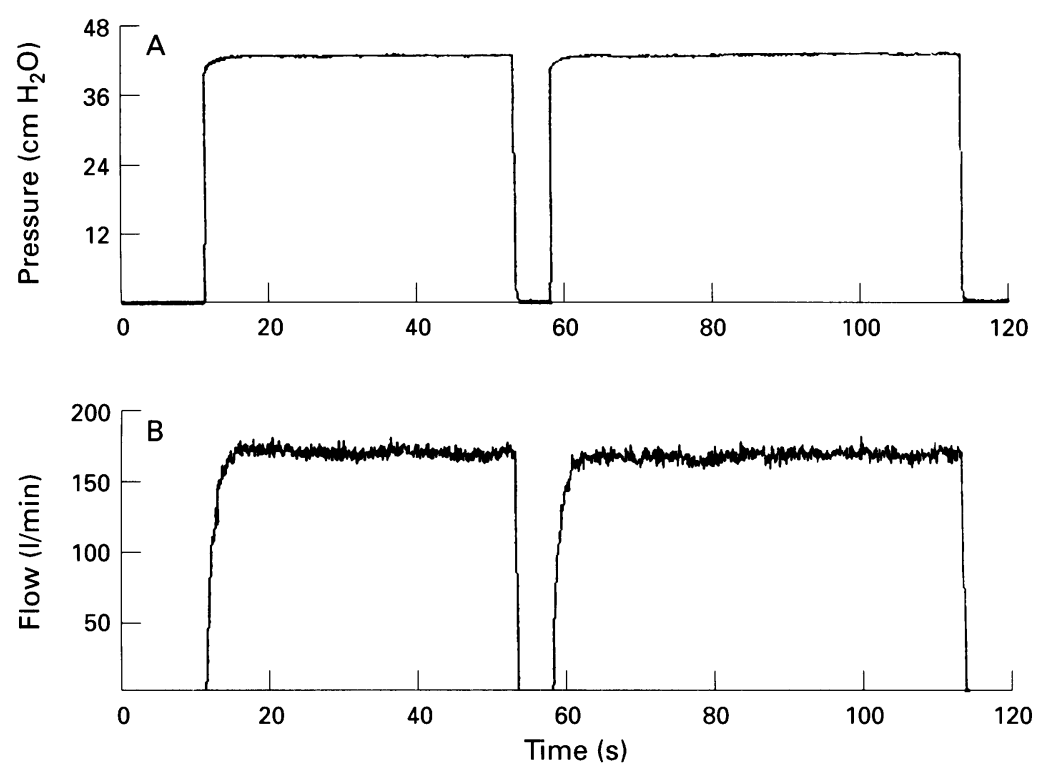

Figure 2 Reconstructed recording of $(A)$ pressure and (B) flow during suctioning of the vacuum pump through the Threshold for two minutes with a short interruption.
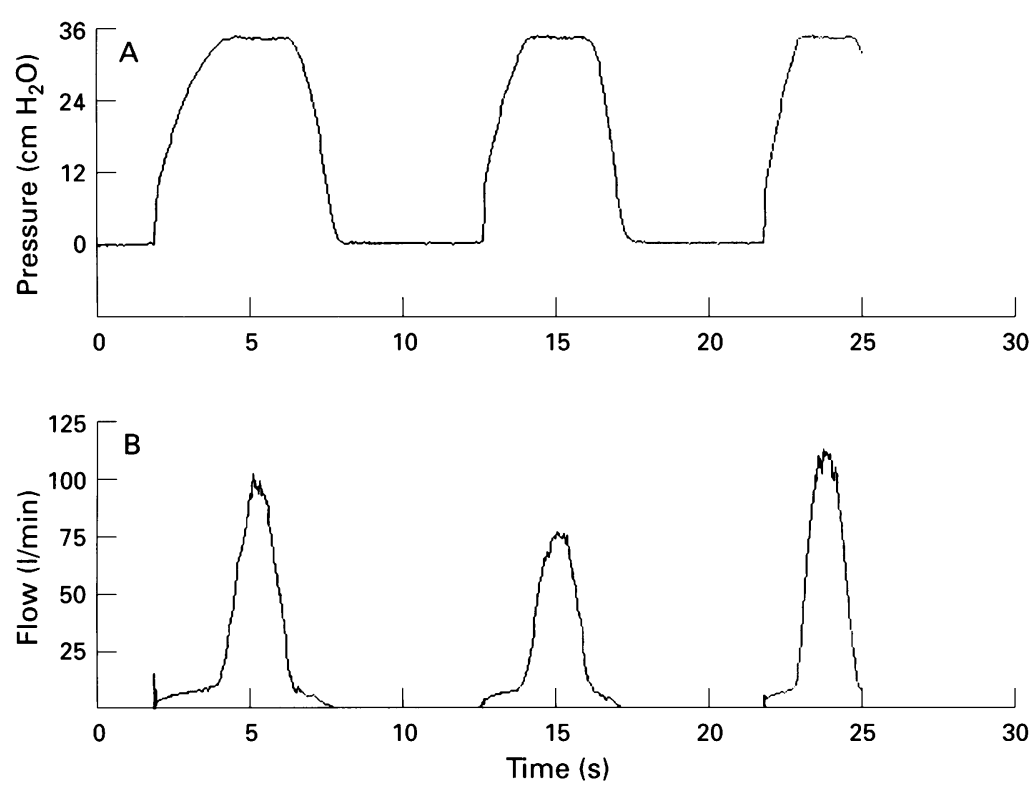

Figure 3 Reconstructed recording of $(A)$ pressure and (B) flow during breathing through the Threshold for 30 seconds in one representative subject. Note that variations in pressure are minor in comparison with the large variations in flow. The small increase in flow before opening of the valve is possibly due to decompression of air in the system and the lungs.
Table 2 Mean (SD) recorded pressure and flow at different preset pressures during the vacuum pump experiment

\begin{tabular}{llr}
\hline $\begin{array}{l}\text { Preset pressure } \\
\left(\mathrm{cm} \mathrm{H}_{2} \mathrm{O}\right)\end{array}$ & $\begin{array}{l}\text { Recorded pressure } \\
\left(\mathrm{cm} \mathrm{H} \mathrm{H}_{2} \mathrm{O}\right)\end{array}$ & $\begin{array}{l}\text { Recorded flow } \\
(\text { l/min })\end{array}$ \\
\hline 20 & $18 \cdot 5(0 \cdot 1)$ & $90 \cdot 5(2 \cdot 0)$ \\
25 & $23 \cdot 0(0 \cdot 1)$ & $97 \cdot 0(2 \cdot 4)$ \\
30 & $28 \cdot 1(0 \cdot 1)$ & $98 \cdot 3(2 \cdot 1)$ \\
35 & $32 \cdot 9(0 \cdot 1)$ & $100 \cdot 7(3 \cdot 2)$ \\
40 & $37 \cdot 9(0 \cdot 2)$ & $90 \cdot 8(4 \cdot 9)$ \\
45 & $43 \cdot 2(0 \cdot 2)$ & $91 \cdot 7(5 \cdot 9)$ \\
50 & $47 \cdot 9(0 \cdot 1)$ & $87 \cdot 2(3 \cdot 4)$ \\
\hline
\end{tabular}

lysed for patients and healthy subjects in the same way as described above. The duty cycle was calculated for each individual at each inspiratory load. The coefficients of variation of the pressure, flow, and duty cycle were then calculated for each load and the mean was determined individually for each patient and healthy subject. Analysis of variance was performed to demonstrate differences in respiratory rate and duty cycle between different levels of loading (25-50\% PImax) and between patients and healthy subjects. Finally, the preset and the recorded pressure were compared by calculating the mean difference and the standard deviation of the difference between these pressures. Differences between patients and healthy subjects were analysed with the MannWhitney U test (StatGraphics, Manugistics Inc, Rockville, Maryland, USA).

\section{Results}

In the first experiment the mean variation of the sustained pressure for all loads was $1 \cdot 7 \%$ and the mean coefficients of variation of pressure and flow measurements were $0 \cdot 2 \%$ and $3 \%$, respectively. Table 2 shows the preset pressures of the Threshold, and the recorded pressure and flow at the six different pressure levels. The changes of the pressures due to variations of the flow were very small (fig 2), indicating that the Threshold is accurate and reproducible under in vitro conditions. The mean (SD) difference between the preset and recorded pressures was $1.9(0.2) \mathrm{cm} \mathrm{H}_{2} \mathrm{O}$. All recorded pressures were systematically lower than the preset pressures.

In the second experiment the healthy subjects showed mean coefficients of variation for pressure and flow of $0.8 \%$ and $20.5 \%$, respectively, and the mean coefficients of variation for the patients were $0.6 \%$ and $14.5 \%$, respectively (fig 3). This means that, although inspiratory flow showed large fluctuations due to adaptations in the pattern of breathing, inspiratory pressure remained constant. In addition, the mean coefficients of variation for flow were significantly higher in the healthy subjects than in the patients $(p<0.05)$. TI/Tтот showed only minor changes during the period of loaded breathing with coefficients of variation for the healthy subjects and the patients of $2 \cdot 1 \%$ and $2 \cdot 5 \%$, respectively (fig 4 ). In addition, no changes were observed between different levels of loaded breathing. However, TI/Tтот showed significant differences between patients $(0.37(0.06))$ and healthy subjects $(0.51(0.08) ; \mathrm{p}<0.0001)$. The respiratory 

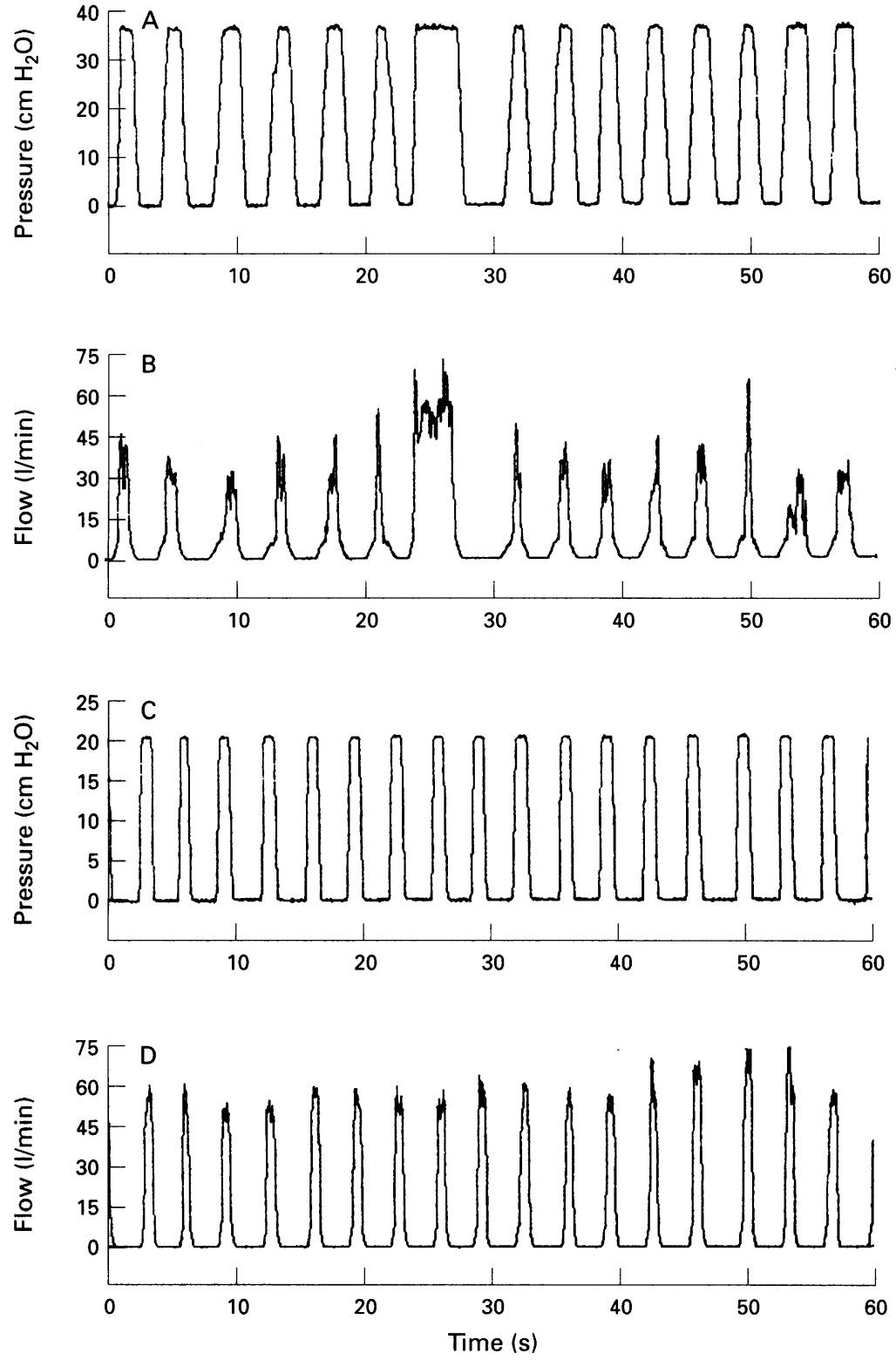

Figure 4 Reconstructed recordings of $(A)$ pressure and $(B)$ flow during breathing through the Threshold for one minute in a healthy subject (note that the seventh breath is a sigh) and of (C) pressure and (D) flow in a patient with chronic obstructive pulmonary disease.

Table 3 Mean (SD) duty cycle and respiratory rate at increasing respiratory load

\begin{tabular}{|c|c|c|c|c|}
\hline \multirow[t]{2}{*}{$\% P ı \max$} & \multicolumn{2}{|l|}{ Respiratory rate } & \multicolumn{2}{|l|}{ Duty cycle } \\
\hline & Healthy subjects & $C O P D$ & Healthy subjects & $C O P D$ \\
\hline $\begin{array}{l}25 \\
30 \\
35 \\
40 \\
45 \\
50\end{array}$ & $\begin{array}{l}14.6(4.5) \\
15 \cdot 1(3.8) \\
15.3(4.8)^{*} \\
15.6(4.7)^{*} \\
17.0(5 \cdot 0)^{*} \\
14.6(3.7)\end{array}$ & $\begin{array}{l}15 \cdot 8(5 \cdot 8) \\
17 \cdot 0(6 \cdot 5) \\
17 \cdot 8(7 \cdot 4)^{*} \\
19 \cdot 5(6 \cdot 6)^{*} \\
19 \cdot 3(5 \cdot 6)^{*} \\
19 \cdot 8(4 \cdot 8)^{*}\end{array}$ & $\begin{array}{l}0.51(0.07) \\
0.51(0.06) \\
0.52(0.06) \\
0.51(0.09) \\
0.53(0.07) \\
0.50(0.09)\end{array}$ & $\begin{array}{l}0.38(0.06) \\
0.37(0.07) \\
0.36(0.07) \\
0.39(0.06) \\
0.37(0.07) \\
0.36(0.07)\end{array}$ \\
\hline
\end{tabular}

Pimax $=$ maximal inspiratory mouth pressure.

* $p<0.05$ compared with $25 \%$ PImax.

rate changed over different levels of loaded breathing $(\mathrm{p}<0 \cdot 01)$. Post-hoc tests revealed significant differences at $35 \%, 40 \%$ and $45 \%$ PImax. No significant differences were observed between patients and healthy subjects $(16.6(6.0)$ and $15 \cdot 8(4 \cdot 0)$, respectively, table 3). The mean difference between the preset and recorded pressures in healthy subjects and patients was $1.7(0.2)$ and $1.8(0.3) \mathrm{cm} \mathrm{H}_{2} \mathrm{O}$, respectively. All recorded pressures were sys- tematically lower than the preset pressures. No significant alterations in oxygen saturation were observed in the healthy subjects or in the patients with COPD.

\section{Discussion}

The first question concerned the determination of the resolution (accuracy) of the Threshold device. We observed only a small variation $(1.7 \%)$ in pressure over a one minute period. The reproducibility of the inspiratory pressure of the Threshold is excellent with a small mean variation of the pressure at different loads in both groups $(<1 \%)$. Independence of the pressure and flow was demonstrated in the second experiment. Again, a small coefficient of variation in pressure was observed in spite of the large changes in flow; the mean coefficient of variation calculated for flow was more than 20 times higher than that calculated for pressure showing that, despite the large fluctuations in flow, the pressure remained constant. Larson et $a l^{20}$ described the independence of flow and pressure of the Threshold very concisely. The pressure remained constant up to a flow of $31 / \mathrm{s}$ and increased by 1 or $2 \mathrm{~cm} \mathrm{H}_{2} \mathrm{O}$ at higher flow rates. No information is given about the applied loads in these tests. In our study the mean flow varied between 0.7 and $2.9 \mathrm{l} / \mathrm{s}$ with a mean of $1.5 \mathrm{l} / \mathrm{s}$. The observation of a very low inspiratory flow at the onset of inspiration effort (fig 2) is due to decompression of the space proximal to the valve including the volume of the lungs. The flow needed for this decompression approximates $5 \mathrm{l} / \mathrm{min}$ and is registered with the mass flow sensor in this part of the circuit (fig 1). This flow was not observed during this and other studies ${ }^{14}$ during in vitro experiments because the volume of a vacuum pump is small.

The respiratory rate increased with higher inspiratory loads but duty cycle did not alter. This contrasts with earlier studies ${ }^{611}$ which observed a decrease in the duty cycle at higher inspiratory loads ( $>45 \%$ PImax $)^{6}$ and an increase again at very high loads. ${ }^{11}$ Bardsley et $a l^{15}$ also found an increase in the duty cycle with the conventional weighted plunger at higher inspiratory loads but no changes with the solenoid valve. Differences in our experiment could be explained by differences in the protocol. In our experiment constant loaded breathing rather than incremental breathing was performed and the maximal load was only $50 \%$ Pimax.

The coefficients of variation of the flow measurements were much higher in healthy subjects than in patients. The patients apparently had less scope for alterations of the breathing pattern and thus less variation in inspiratory flow. The duty cycle during loaded breathing was shorter than in the healthy subjects. As respiratory rate, and thus TTOT, were not significantly different, inspiratory time was shorter in patients.

In all experiments (in vitro and in vivo) a systematically lower pressure of about $2 \mathrm{~cm}$ $\mathrm{H}_{2} \mathrm{O}$ was recorded compared with the preset value. This was possibly due to replacement of 
the original one way valve with a closed valve of a similar diameter and weight.

The conclusion that a fairly constant pressure is obtained with the Threshold device does not automatically mean that a constant power output of the inspiratory muscles is assured. The product of pressure and time (pressuretime product) over a given period of time gives more insight into the power output of the respiratory muscles. ${ }^{21}$ In the formula: PI $\times$ TI $\times \mathrm{RR}=\mathrm{PI} \times \mathrm{TI} \times 1 /$ TTоT $=\mathrm{PI} \times \mathrm{TI} /$ Tтот where $\mathrm{PI}=$ inspiratory pressure, $\mathrm{TI}=$ inspiratory time, Tтот $=$ respiratory cycle time, $R R=$ respiratory rate. As we found a very low coefficient of variation for the duty cycle $(\sim 2 \%)$, this means that the pressuretime product was also constant. The Threshold device was therefore able to generate a constant power output of the inspiratory muscles. ${ }^{22}$

\section{PRACTICAL IMPLICATIONS}

The assessment of respiratory muscle endurance and training of respiratory muscles was successful in various studies with the Nickerson and Keens' system. ${ }^{5121320}$ For the implementation of these findings in clinical practice a commercially available device is required. Our study shows that the Threshold meets the demands for reliable inspiratory loading in both assessment and training of inspiratory muscles.

Recent studies on respiratory muscle training report that, not only is improvement of endurance and strength of the respiratory muscles achieved, but improvements were also observed in exercise capacity and dyspnoea during activities of daily living in patients with ventilatory limitation during exercise. ${ }^{12224}$ All these studies have in common the careful control of the target pressure during training, one of them with threshold loading. ${ }^{12}$ This suggests that the reliability of the inspiratory load is essential.

However, no data are presently available to support resistive or threshold loading as the training method of choice. Threshold loading requires build up of negative pressure before flow occurs, and hence is inertial in nature. Whether resistive loading or inertial loading produce different training effects remains to be studied. ${ }^{25}$ Belman et al ${ }^{26}$ observed similar work of breathing during resistive and threshold loading. Application of the solenoid valve has the disadvantage of pressure generation only at the onset of inspiration, resulting in a significantly lower pressure-time product compared with the weighted plunger device. ${ }^{15}$

An area for the specific application of threshold loading could be training of inspiratory muscles in patients during weaning from mechanical ventilation. As these patients are frequently unable to cooperate actively with the training, a load independent of breathing pattern - that is, threshold loading - is necessary.

In conclusion, this study shows that during threshold loading only small variations in pressure were observed despite large variations in flow. In addition, the pressure-time product was constant during loaded breathing. The Threshold is therefore a reliable and reproducible device for loading inspiratory muscles.

This study was supported by the Nederlands Astma Fonds and the Fonds voor Geneeskundig Wetenschappelijk Onderzoek (Levenslijn Grant \# 7.0002.94)

1 Leith DE, Bradley ME. Ventilatory muscle strength and endurance training. F Appl Physiol 1976;41:508-16.

2 Nickerson BC, Keens TG. Measuring ventilatory muscle endurance in humans as sustainable inspiratory pressure. endurance in humans as sustain

3 Belman MJ, Shadmehr R. Targeted resistive ventilatory muscle training in COPD. $\mathcal{f}$ Appl Physiol 1988;65:272635.

4 Morrison NJ, Richardson J, Dunn L, Pardy RL. Respiratory muscle performance in normal and elderly subjects and patients with COPD. Chest 1989;95:90-4.

5 Goldstein R, De Rosie J, Long S, Dolmage T, Avendano MA. Applicability of a threshold loading device for inspiratory muscle testing and training in patients with COPD. Chest 1989;96:564-71.

6 Martyn JB, Moreno RH, Pare PD, Pardy RL. Measurement of inspiratory muscle performance with incremental of inspiratory muscle performance with incremental

7 Clanton TL, Dixon GF, Drake J, Gadek JE. Effects of breathing pattern on inspiratory muscle endurance in breathing pattern on inspiratory muscle
humans. $\mathcal{f}$ Appl Physiol 1985;59:1834-41.

8 Clanton TL, Ameredes BT, Thomson DB, Julian MW. Sustainable inspiratory pressures over varying flows, volumes and duty cycles. $\mathcal{f}$ Appl Physiol 1990;69:1875-82.

9 McElvaney G, Fairbarn MS, Wilcox PG, Pardy RL. Comparison of two-minute incremental threshold loading and maximal loading as measures of respiratory muscle endurance. Chest 1989;96:557-63.

10 Gosselink RAAM, Wagenaar RC, Sargeant AJ, Rijswijk H, Decramer MLA. Diaphragmatic breathing reduces efficiency of breathing in chronic obstructive pulmonary disease. Am 7 Respir Crit Care Med 1995;151:1136-42.

11 Eastwood AR, Hillman DR, Finuncane KE. Ventilatory responses to inspiratory threshold loading and role of muscle fatigue in task failure. I Appl Physiol 1994;76: $185-9$.

12 Lisboa C, Munoz V, Beroiza T, Leiva A, Cruz E. Inspiratory muscle training in chronic airflow limitation: comparison of two different training loads with a threshold device. Eur Respir 7 1994;7:1266-74.

13 Clanton TL, Dixon GF, Drake J, Gadek JE. Inspiratory muscle conditioning using a threshold loading device. Chest 1985;87:62-6.

14 Eastwood PR, Hillman DR. A threshold loading device for testing of inspiratory muscle performance. Eur Respir $\mathcal{F}$ 1995;8:463-6.

15 Bardsley PA, Bentley S, Hall HS, Singh SJ, Evans DH, Morgan MDL. Measurement of inspiratory muscle per-
formance with incremental threshold loading: a comformance with incremental threshold loading: a
parison of two techniques. Thorax 1993;48:354-9.

16 American Thoracic Society. Standardization of spirometry. 1987 update. Am Rev Respir Dis 1987;136:1285-98

17 Quanjer PH, Tammeling GJ, Pedersen OF, Peslin R, Yernault JC. Lung volumes and forced expiratory flows. Eur Respir ₹ 1993;6(Suppl 16):5-40.

18 Black LF, Hyatt RE. Maximal respiratory pressures: normal values and relationship to age and sex. Am Rev Respir Dis 1969;99:696-702.

19 Bland JM, Altman DG. Statistical methods for assessing agreement between two methods of clinical measurement. agreement between two

20 Larson JL, Kim MJ, Sharp JT, Larson DA. Inspiratory muscle training with a pressure threshold breathing device in patients with chronic obstructive pulmonary disease. in patients with chronic obstructive
Am Rev Respir Dis 1988;138:689-96.

21 Collett PW, Perry C, Engel LA. Pressure-time product, flow, and oxygen cost of resistive breathing in humans. $\mathcal{F}$ Appl Physiol 1985;58:1263-72.

22 Homan S, Moran J, Adams R, Filsell S, Leppard P. Effect of inspiratory threshold loading and inspiratory flow upon respiratory muscle performance and oxygen uptake. Eur Respir $\mathcal{F}$ 1995;8:379s (abstract).

23 Dekhuijzen PNR, Folgering HTM, van Herwaarden CLA. Target-flow inspiratory muscle training during pulmonary rehabilitation in patients with COPD. Chest 1991;99:12833 .

24 Wanke T, Formanek D, Lahrmann $H$, Brath $H$, Wild $M$, Wagner $\mathrm{Ch}$, et al. The effects of combined inspiratory muscle and cycle ergometer training on exercise performance in patients with COPD. Eur Respir $\mathcal{F} 1994 ; 7$; 2205-11.

25 Gosselink R, Decramer $M$. Inspiratory muscle training: where are we? Eur Respir $\mathfrak{f}$ 1994;7:2103-5.

26 Belman MJ, Warren CB, Nathan SD, Chon KH. Ventilatory load characteristics during ventilatory muscle training. $\mathrm{Am}$ $\Im$ Respir Crit Care Med 1994;149:925-9. 